\title{
FAMÍLIAS E AGRUPAMENTOS: SOBRE SEUS DOMÍNIOS E DIVERSIFICAÇÕES
}

\author{
Pâmella Synthia Santana Santos 1
}

\begin{abstract}
Resumo: Este artigo, que provém tanto de uma pesquisa já concluída, como de uma em andamento, tem por objetivo debater sobre a relação entre os agrupamentos e famílias políticas e redes sociais que constituem o quadro políticopartidário do estado de Sergipe partindo tanto da política local e de como ela se insere no contexto estadual. O universo empírico consiste na análise das eleições de 2014, seus atores (cabos eleitorais, candidatos a deputados, senadores, governadores) e como as relações entre esses estão inseridos nas configurações e manutenções dessas famílias políticas. As técnicas metodológicas deste trabalho são análise de documentos, observação participante e entrevistas semiestruturadas. É frisado no trabalho em questão que não é somente na política que essas famílias e agrupamentos encontram-se impregnados com suas redes de relações, pois estão presentes também, por exemplo, no meio empresarial, midiático, médico, judicial, e etc. Com isso, as constatações desse trabalho mostram que por mais que estejam em lados opostos na política, acaba sendo frequente a participação de atores que fazem parte de outros grupos justamente pela diversificação de espaços, mas que em alguns casos, essa grande diversificação, acabando também por modificar o peso do nome da família em si, por acabar diminuindo sua participação.
\end{abstract}

Palavras-chave: política partidária; famílias; agrupamentos; redes.

\section{FAMILIES AND GROUPS: ON THEIR DOMAINS AND DIVERSIFICATIONS}

\begin{abstract}
This article, which comes from a research already completed, as an ongoing research, aims to discuss the relationship between political groupings and families and social networks that constitute the political-partisan framework of the state of Sergipe starting from both the Local politics and how it fits into the state context. The empirical universe consists of the analysis of the 2014 elections, their actors (electoral cables, candidates for deputies, senators, governors) and how the relations between them are inserted in the configurations and maintenance of these political families. The methodological techniques of this work are document analysis, participant observation and semistructured interviews. It is emphasized in the work in question that it is not only in politics that these families and groups are impregnated with their networks of relationships, for they are also present, for example, in the business, media, medical, judicial, and so on. With this, the findings of this work show that however much they are on opposite sides of politics, it is often the participation of actors who are part of other groups precisely because of the diversification of spaces, but in some cases, this great diversification, For changing the weight of the family name itself, by eventually reducing their participation.
\end{abstract}

Keywords: partisan politics; Families; Groupings; Networks.

- Enviado em 15/07/2017

- Aprovado em 28/07/2017

\footnotetext{
${ }^{1}$ Doutoranda no Programa de Pós-Graduação em Sociologia na Universidade Federal de Sergipe

Uma versão preliminar desse texto foi apresentada no $18^{\circ}$ Congresso Brasileiro de Sociologia. Que Sociologia fazemos? Interfaces com contextos locais, nacionais e globais realizado de 26 a 29 de julho de 2017 no Centro de Convenções Ulysses Guimarães, Brasília/DF.
} 


\section{Introdução}

Este artigo tem por objetivo debater sobre a relação entre os agrupamentos e famílias políticas e redes sociais que constituem o quadro político-partidário do estado de Sergipe partindo tanto da política local e de como ela se insere no contexto estadual. Para isso, parte-se de uma pesquisa já concluída ${ }^{2}$, a nível de Mestrado, onde debateu-se a fabricação e o papel do cabo eleitoral nas eleições, e como desdobramento, ficou evidente a relação que esses cabos tem com os vários agrupamentos, além de eles poderem transitar sem terem as suas escolhas tão questionadas assim. Excetua-se também o fato de que os agrupamentos acabavam se encontrando com determinados integrantes que fizeram suas relações para além dos seus grupos, isso com o propósito da diversificação. Mas até que ponto isso é válido como estratégia política? Parte-se também de uma pesquisa atual, a nível de Doutorado que busca tratar dessa relação pensando na dinâmica estadual, e conseguir investigar essas redes entre famílias e agrupamentos.

Não é somente com os grandes políticos que conseguiremos enxergar essas nuances, mas também com aqueles que agregam os seus grupos. Levando em consideração a abordagem utilizada por Queiróz (1976) sobre o que seria a família brasileira, pois ela comporta outros indivíduos além daqueles “de sangue". Se valerá também de observações feitas durante o período eleitoral de 2014 e 2016 para consolidar as análises feitas sobre como a política estadual se portou levando em consideração as relações necessárias para o êxito eleitoral. As entrevistas semi-estruturadas que compõem no corpo deste trabalho foram realizadas no mesmo período que possibilitaram compreender mais a perspectiva desses atores sobre as suas próprias relações e como são feitas e mantidas. Destaco também que os nomes contidos (atores, grupos, famílias, município) na segunda parte do trabalho foram alterados como precaução para ambos os lados, assim como foi feito em todo o trabalho inicial (SANTOS, 2016).

O ponto de partida para essa análise são deputados (estaduais e federais) eleitos em 2014 e dos senadores eleitos em 2010 e 2014, devido ao fato dos números de candidatos eleitos nos dois pleitos (dois em 2010 e um em 2014). É a partir daí então que selecionamos os casos mais aparentes, ou seja, aqueles que já indicam o recurso familiar como recuso político, utilizando então os "nomes de famílias" para destacá-los e então, podermos chegar - ou não - aos outros atores políticos, observando os agregados, apadrinhamentos, matrimônios, que compõe a "parentela" e

\footnotetext{
${ }^{2}$ SANTOS, 2016.
} 
assim, poder identificar a rede de relações presentes na política sergipana, isso porque um conjunto recente de trabalhos (CANEDO, 2002, 2004, 2011; CORADINI, 2001; GRILL, 2004, 2007, 2008, 2012) tem demonstrado que as famílias compõem o cotidiano da política em diferentes espaços nacionais.

Esta problemática tem sido apresentada como um elemento constitutivo do ofício político, contudo é necessário compreender de que forma as relações de base familiar passam a compor a atividade política e como em certa medida, no que diz respeito à realidade brasileira, ela se torna cada vez mais diversificada. É nessa direção que um conjunto de estudos sobre a política no Brasil tem destacado mais do que "nomes de famílias" as relações de base familiar. A ideia de relações familiares permite ampliar o leque de possibilidade dos vínculos familiares utilizados para garantir a iniciação na política (BLONDEL, 1957; DANTAS, 1997; LEWIN, 1993; QUEIRÓZ, 1976), e assim cristalizar as bases familiares. É a partir desses atores que poderemos então entender o que viria a ser o profissional da política, a utilização do recurso familiar e os agrupamentos existentes no estado, situação essa remonta a décadas passadas. Logo, é sabido que essa relação que propomos como objeto de pesquisa é uma situação existente e que constitui a política e o "vir a ser" político e esse político não está situado somente nesse espaço, mas é necessário percorrer o caminho que leve a outros recursos.

\section{POLÍTICA PROFISSIONAL E AGRUPAMENTOS}

Sobre os deputados e senadores que destacaram o recurso familiar, vemos uma diversificação de famílias e municípios do Interior do Estado além de que a sua constituição e crescimento se deu durante o período da ditadura militar e da divisão dos partidos entre ARENA e MDB, onde a participação deste primeiro era superior a do segundo, vindo a existir uma subdivisão: ARENA I e ARENA II. No interior sergipano essa divisão era recorrente devido ao fato de que o MDB não tinha grande participação além de que os coronéis e seus aliados faziam parte da rede de relações dos líderes da ARENA (MONTALVÃO, 2011), principalmente quando o ex-governador Augusto Franco conseguiu êxito no governo do Estado e que foi a partir daí, contribuindo para a sua consolidação e de sua família na política, que tinha começado com o seu irmão Valter Franco. As famílias que vemos hoje representadas pelos deputados e senadores, a maioria delas teve o seu início na política através das alianças com a família Franco, que estavam inseridos em outros espaços profissionais como na Medicina e na Indústria. É interessante destacar essa família porque ela foi considerada por muito tempo a principal mandatária da política sergipana, devido a sua 
grande rede de relações, mas que atualmente não está tão em evidência, por nenhum integrante seu estar ocupando um cargo eletivo. O que se vê hoje em dia é um conjunto de famílias e grupos aumentando os seus espaços na política eletiva e a diversificação de relações dos mesmos, que a cada pleito, seja ele municipal ou estadual, estão se interligando cada vez mais.

Partindo do que foi exposto, colocamos as tais "famílias políticas", mencionando apenas os seus nomes: Franco (em Aracaju, a união com a família Franco ocorreu através de vários matrimônios como também com a família Rollemberg, Prado e Pimentel), Moura (Aracaju/Pirambu) Reis e Ribeiro (Lagarto), Teles de Mendonça (Itabaiana), Fonseca e Mitidieri (Boquim), Valadares (Simão Dias), Monteiro (Salgado/Lagarto), Passos (Ribeirópolis) Góis (Riachão do Dantas). Além dessas famílias, há outras que se encontram em suas redes, com aliados e apadrinhados como algumas que se concentram na Capital, vide a família Alves e a família Amorim, além de outras que tem uma proporção menor, como os Hagenbeck (Laranjeiras). Serão a partir delas que poderemos identificar os agrupamentos e seus integrantes "agregados", seja pelo apadrinhamento, como também pelo matrimônio.

Por se tratar de grupos, famílias e atores políticos que estão historicamente impregnados na política sergipana, conhecer a história social desses grupos, ou melhor, das suas redes é crucial para entender o seu desenvolvimento e como ocorreu a sua participação nas principais esferas sociais, reconvertendo assim para a política. Além de se consolidarem em seus municípios, as famílias aumentam o seu capital político no momento em que passaram a disputar cargos eletivos para além do âmbito local, opondo-se a outras famílias e grupos na disputa eleitoral. Uma forma de manutenção na condição de família dirigente é expandir os cargos como também se inserirem em outras esferas, como administrativa, empresarial, escolar e etc.. A socialização dos indivíduos ocorre em diversos domínios da sociedade, como a cultura, a religião, a tecnologia e a política, nos quais tomam lugar as diversas experiências que contribuem particularmente para o processo de construção da identidade social e da autoimagem do indivíduo em relação ao sistema político e às instituições da sociedade. Para os deputados e senadores que foram inclusos como universo empírico do estudo, tanto o jogo político quanto o social são duas faces de uma realidade, mas, para que esses atores conservem o poder adquirido, é necessário que aja não apenas como um profissional da política, mas como um mestre em ambas as faces desse jogo.

Sobre essa discussão, a Sociologia, aliada à Ciência Política e à Antropologia, tem muitos trabalhos que buscam entender pelo menos um desses pontos apresentados. Para tanto, pensando na Sociologia dos Grupos Profissionais, iremos nos baseamos nos trabalhos de Phelippeau (2010), Sawicki (1999) e Offerlé (1999) para entender sobre a formação da política como profissão e como 
ela conseguiu o seu espaço legitimado - não pensando em credenciais ou aporte jurídico, mas sim como ofício reconhecido e necessário para a manutenção da representação - além de proporcionar o levantamento de questionamentos acerca dessa categoria profissional; a ideia de política como vocação e profissão de Weber que acaba sendo refletida em outros trabalhos como os de Lehingue (1999), Briquet (1999), Bacot (1999) que podemos aliar à questão da identidade profissional de Dubar (1998) juntamente à noção de carreira de Becker (2008) e conversão à profissão de Hughes (1964). Já na Sociologia da Política, nos baseamos na ideia de redes sociais, parentela, famílias e heranças políticas, apresentadas por Lewin (1993), Queiróz (1976), Canedo (2002, 2004, 2011), Grill (2004, 2007, 2008, 2012, 2013) e Saint-Martin (1992, 2008); na questão da base eleitoral com Bezerra (1999) e Kuschnir (2000) e dos agrupamentos e facções pensados por Palmeira (1998), Palmeira e Barreira (2004), Palmeira e Heredia (2010), Camargo (2012), Landé (1977) e Carvalho (1997); devemos pensar também no que consiste os grupos dirigentes e seus recrutamentos, como Coradini (2001), Love e Barickman (2006).

A partir daí é necessário compreender esse ofício por uma descrição das funções e relacionamentos envolvidos nesse estilo de vida. $\mathrm{O}$ entendimento dessa culta é um pré-requisito para o entendimento do que é um "político profissional". Phelippeau (2010) analisa a sociogênese da profissão política na França, país em que ela deixa de ser uma ocupação de "notáveis" e passa a ter mais participação dos chamados "amadores". Nesse caso, o recurso a que será dado o maior foco é o recurso familiar aliado a outros recursos. Logo, famílias que conseguem mobilizar suas redes para adentrar no espaço político e nele se manterem, necessariamente precisam diversificar seus recursos como também as suas redes de relações. Seja no campo econômico, profissional, cultural e etc., essas famílias devem mobilizar os diversos capitais para serem consideradas famílias políticas, as quais constituem os grupos dirigentes, pois somente assim conseguem se diversificar. Entretanto, é importante destacar o posicionamento tanto do ator político como daqueles que não fazem parte desse espaço em relação ao que viria a ser um "político profissional". Trabalhos realizados na França demonstram essas visões. Por ocupações não reconhecidas ou até mesmo que não haja um credenciamento como um diploma superior, a Sociologia está cheia de estudos com esses tipos.

Estudos como esses nos proporcionam identificar elementos muito interessantes pelo fato de esses ofícios não serem caracterizados como qualquer outro regulamentado. Um dos fatos que sempre é mencionado por esses profissionais quando se é questionado se eles consideram atuar na política como profissão, é sempre colocado que o trabalho deles é mera vocação e ou "vontade de ajudar ao povo", que seriam "alguém que foi eleito para servir a população", através dos mecanismos disponíveis do legislativo ou executivo. Offerlé (1999) aborda os vários sobre 
trabalhos acerca da profissão política em diversas visões, seja sobre a legitimação da profissão, da crise de identidade política, das profissões que encaminham para a política profissional, etc., mostrando a importância de dar espaço para essa "profissão" ser analisada. Para Canedo (2002), designar a política como a atividade principal de uma vida implica considerar as diferentes maneiras de entrada, assim como as chances diversas que são oferecidas aos entrantes, as margens de liberdade de ação para exercer o que se convencionou a chamar de "artes da política". Qualquer cidadão, preenchendo as condições definidas por lei, pode se candidatara um mandato eletivo, o qual é juridicamente temporário, pois os eleitores podem votar num outro candidato, quando das eleições seguintes. Todavia, há exigências preliminares que não se encontram escritas na lei e que condicionam o ingresso e a saída da vida política. Kuschnir (2000) ao se propor a analisar o cotidiano da política de uma vereadora do Rio de Janeiro, e que seu pai também era um político profissional, pode demonstrar a importância de o ator já ser apresentado à essas artes da política para quando chegar na prática, poder lidar tanto com a imagem como também na aplicação do saber. A proposta desse projeto caminharia por esse viés, de compreender como filhos, netos, ou qualquer outro parente e/ou apadrinhado adentra nos mesmos caminhos que seus precursores, reproduzindo o nome da família ou do seu grupo.

O caso estudado por Lehingue (1999) na França, que tinha por objetivo analisar as disputas do jogo político em relação a tentativa de regulação da profissão política, mostrou que entre os próprios políticos havia a divergência de elevar a política a uma profissão reconhecida, ou seja, é colocado como as relações de disputas sobre uma profissionalização da política com respaldos jurídicos, isso em cima de um conjunto de debates no congresso. Debates esses que giravam em torno de tudo que proporcionava a uma profissão ser reconhecida como tal; a discussão entra agora na definição convencional de uma profissão: a adesão de um plano de pensão, o direito à formação, horas de crédito, às folhas de ausência, filiação do regime geral da segurança social, reabilitação substancial, a normalização e a tributação das prestações.

Construir um monopólio profissional em um determinado setor de atividade social é estabelecido pelos procedimentos de seleção institucionais e de controle formal, e os membros do grupo profissional asseguram-se do controle de gestão e baseia-se na forte racionalização do conhecimento e experiência que constituem o exercício da profissão. É ainda é baseado de acordo a procedimentos que a "ocupação" não pode controlar, porque como é através da votação, eles dependem de mecanismos externos que este grupo nunca pode garantir controle total. $\mathrm{O}$ recurso familiar não consegue dar conta de todo o peso que se tem para se manter na política, pois é necessário aliar ele a outros tipos de recursos, por mais que estejamos colocando aqui a política 
profissional como ocupação, pois como qualquer outro espaço profissional, elementos variados devem estar ligados como base, assim como vemos com Coradini (2001) e com isso, vemos que os nossos exemplos de atores políticos estão inseridos em outros espaços como também há uma variação de áreas ocupacionais e de capital escolar; tudo isso para compor, enfim, a imagem de um político profissional.

Aliado ao que falamos um pouco acima e não muito diferente, Bacot (1999) coloca como os atores veem a política, no caso, como a política é representada para eles e como os políticos se auto representam. Como em qualquer outro local, a sociedade em si vê o político como um privilegiado entre outros privilegiados, uma pessoa que ocupa um espaço totalmente diferente do espaço comum, justamente pela visão que os atores sociais têm do político. Além disso, também está em negação a representação do mundo político, ou seja, há uma incompatibilidade entre a auto representação do político e a sua própria imagem. Os políticos profissionais possuem competências e habilidades referentes ao que devem exercer no cargo, como há várias pesquisas que trabalham essa questão da atuação do político profissional, entretanto, quando se fala em representação e gerenciamento das atividades políticas, eles são vistos como integrantes de uma casta, e tendo como seu principal know-how a predisposição a enganar, além de somente buscarem a existência, permanência e defesa de seus privilégios.

A dinâmica de lutas entre facções marca as disputas políticas no Brasil e realça o papel das redes políticas. Pode-se indicar a configuração de teias de relações que são maximizadas pelos indivíduos e que se caracterizam pela confluência de aspectos como: a inexistência de um conteúdo de união incorporado ou de uma ideologia comum; a incerteza com relação a sua durabilidade; e a organização em torno de interesses, rivalizando com outras facções similares (CAMARGO, 2012; LANDÉ, 1977; PALMEIRA 1996; PALMEIRA, BARREIRA, 2004; PALMEIRA, HEREDIA, 2010). Devido à conjuntura partidária brasileira bastante diversa, a utilização de redes de apoio e alianças de diversos tipos é necessária para uma família ou até mesmo para várias famílias almejarem postos eletivos.

O recrutamento de novas lideranças no seio da própria elite política e a consequente transmissão do poder entre membros da mesma família ou de uma mesma rede de base familiar apresenta-se como um dos caminhos de resgate ou perpetuação do reconhecimento, pois a reclamação da qualidade de "especialista político" está diretamente ligada aos movimentos de retenção de "tradições familiares" dentro do espaço político (GRILL, 2008, p. 21). Como exemplo, cite-se a família Valadares que tem uma grande trajetória na política sergipana e na história política do município de Simão Dias, onde vários integrantes almejaram o cargo de prefeito do município, 
mas que foram além, já que, através de mandatos como os de deputado estadual e federal, conseguiu alcançar os cargos de governador e, atualmente, um alto posto eletivo, o de Senador Federal.

Por isso que é pertinente usar a noção de redes - colocada por Queiróz (1976) e Lewin (1993) e não pensar somente a questão das grandes famílias com Saint-Martin $(1992,2008)$-, principalmente na política, porque a política sergipana (a brasileira de um modo geral, como estudos que serão mencionados mais à frente poderão afirmar) se fez e se consagrou como uma política de base familiar, não somente de uma família, mas de várias famílias, ligadas por diversos aspectos, seja pelo elo econômico, matrimônios, ou outros interesses em comum, que se aliaram para ter a possibilidade de comandar um determinado local (povoados, cidades, Estado). A partir daí, para compreender a dinâmica política estadual que se encontra representada na Assembleia Legislativa e na Câmara dos Deputados, é importante analisar o background dessas famílias, pelo fato de elas fazerem o cotidiano da política continuar ávido em suas cidades natais. Separadamente, elas podem não aparentar que fazem alguma diferença na política estadual, mas a questão se encontra no conjunto delas e nas relações que elas estabelecem, pois cada uma tem uma participação efetiva nos municípios que as fizeram ascender.

\section{DA CASA PARA A POLÍTICA: UM CASO SERGIPANO}

Faz parte da história do país o controle de setores da vida cotidiana por grupos familiares e mesmo com o fim do sistema político coronelismo, chefes políticos permaneciam operando o domínio da política, economia, saúde, etc. Essas famílias conseguiam diversificar seus recursos, possibilitando a sua presença nos variados setores, e em Sergipe, vemos o caso mais exemplar na Medicina (PETRARCA, 2017). Já há uma certa naturalidade e aceitação por parte da sociedade em se ter grupos que estão à frente. A presença desses grupos na política é a mais visível por parte da sociedade, pois é necessária a relação entre ambos para que esses grupos permaneçam à frente. Devido a esse grande contato, é importante a reflexão sobre com quem manter vínculo, como diversificar sem deixar a sua zona de conforto. Em Sergipe, a família Franco conseguiu construir o seu nome em vários espaços, estando hoje à frente das emissoras de tv no estado, no setor industrial, do empresariado do ensino superior, e na política que por muito tempo controlaram, hoje se encontram nos bastidores, aparecendo mais no chamado "tempo da política", mas não deixam de demonstrar as suas relações e capacidade de renovarem as suas forças. Mas ela não pode ser considerada a "grande família" do Estado, vide a limitação desse termo devido a constituição da 
família brasileira, que é totalmente diferente daquela onde o termo surgiu teoricamente (CANDIDO, 1951).

O presente trabalho segue a linha do autor citado acima, como também a de Queiróz (1976) que seria a de que a família, em seu aspecto nuclear, não conseguiria dar conta das dinâmicas sociais, e com isso, a presença dos agregados faria a diferença necessária para conquistar a diferenciação e destaque em vários espaços. Segue-se essa linha porque, como será visto mais à frente, a mobilidade de integrantes desses grupos é o que faz a política se dinamizar, por mais que a mesma possa muitas vezes estar mascarada pelas filiações partidárias e "posicionamentos ideológicos" diferentes. A questão central então seria em como conseguir esses apoios sem comprometer diretamente os grupos. Pelo menos durante o "tempo da política", seria através dos cabos eleitorais que essa mobilidade seria possível. A facção que assume o controle de um município - sintomaticamente identificada pelas demais e autorreferida como "situação" - é, de modo quase automático, associada à política institucional, à política "externa" e legítima, ao governo (entidade que corporifica o poder externo), e as demais postas na posição residual de “oposição". Sua pretensão não é propriamente representar a comunidade, mas ser reconhecida pelos de fora e projetar-se para dentro como se fosse toda a comunidade (PALMEIRA; BARREIRA, 2004).

Tendo já sido consolidadas as alianças, as facções políticas em Arapongas ficaram com aspectos diferentes das eleições estaduais de 2010, como também a municipal em 2012. As famílias Vieira e Ferreira e os seus respectivos grupos políticos Matamatá e Cochara tiveram os seus nomes representados nas eleições de 2014 com a candidata à reeleição, a deputada estadual Mara Vieira (DEM); o candidato à reeleição, o deputado federal Marcel Vieira (PMDB), e o candidato à reeleição a deputado estadual Julinho Ferreira (PSD). Nas eleições de 2014, o grupo Matamatá optou por apoiar o candidato ao governo Benjamim Azevedo (PMDB), que tinha o apoio do PT, partido que apoiou o ex-prefeito de Arapongas nas eleições de 2012; e Jonatas Oliveira (PSC), que também se candidatou a deputado estadual, todavia, em 2014, apoiou Daniel Caetano (PSC) ao governo. Daniel Caetano teve o apoio de um grande político da capital sergipana e esposo da candidata ao senado Luciana Almeida, sendo que esta última recebia o apoio de Mara Vieira, esta, por sua vez, não declarava nos comícios nem em seu material de campanha qual governador estaria apoiando. Julinho Ferreira tinha o apoio de sua família, que também fazia campanha para o candidato do PT ao senado Ricardo Lemos.

Interessante observar que com essas alianças, fica perceptível como a configuração dos grupos políticos mudou efetivamente, pois, necessariamente, quem faz parte do grupo Matamatá 
apoiaria os candidatos do seu grupo, mesma coisa com os do Cochara. Todavia, na prática, os apoios não levaram tanto em consideração o "ser cochara" e "ser matamatá". Na inauguração do comitê da candidata à reeleição, a deputada estadual Mara Vieira, uma "confusão" de apoios se caracterizou de uma forma que até então não tinha acontecido nas campanhas em Arapongas, seja em nível municipal ou estadual. Sendo a candidata do Matamatá, necessariamente as lideranças do grupo a estariam apoiando. No trio elétrico, no momento dos discursos, o locutor sempre falava nomes de candidatos e os seus respectivos números: Mara Vieira, 25983; Marcel Vieira, 1599; Luciana Almeida, 258; Benjamim Azevedo, 15; e Aécio Neves, 45; mas quando Luciana Almeida estava presente, o locutor só falava o seu número e o de Mara. Havia a distribuição de adesivos de Mara e Marcel Vieira, Luciana Almeida e Aécio Neves. Mara só usava os adesivos dela, de seu sobrinho e de Luciana Almeida. E as bandeiras eram somente da própria Mara e de Marcel Vieira. Apesar de ele não estar presente fisicamente, a sua imagem era sempre lembrada.

Com essa chapa, percebe-se a confusão entre os apoios e mistura de coligações adversárias. Mara Vieira, Luciana Almeida e Aécio Neves pertenciam a uma coligação, e Marcel Vieira e Benjamim Azevedo pertenciam à outra. Mara Vieira, do DEM, foi secretária da Saúde da capital, onde o esposo de Luciana Almeida era prefeito e assim já vinham se aliando desde eleições anteriores, nas quais o partido de Luciana Almeida, o DEM, aliou-se ao PSDB, partido de Aécio Neves, e do prefeito de Arapongas, Vagner Freire. Mas Marcel Vieira, sendo o principal candidato a deputado federal do Matamatá, pertence ao mesmo partido que Benjamim Vieira, adversário de Daniel Caetano, do PSC, que tinha como candidato à presidência Aécio Neves, e aliado a Luciana Almeida. O prefeito Vagner pediu voto para Mara Vieira, utilizando do discurso familiar, dizendo que Jonas Vieira é um grande homem, de bom coração, que nunca mediu esforços para ajudar a quem precisasse. Pediu voto pra Aécio Neves, dizendo que Dilma e Lula, junto com o PT, acabaram com o Brasil. Todavia, Marcel Vieira estava com Benjamim, que tem apoio de Dilma e é coligado com o PT. Também pediu voto para Benjamim, justificando que o mesmo ajudou com o asfalto em Arapongas, porém, não pediu voto para Luciana Almeida. Os gráficos a seguir irão demonstrar esse mosaico de alianças: 


\section{Gráfico 1 - Relação entre os grupos e os candidatos}

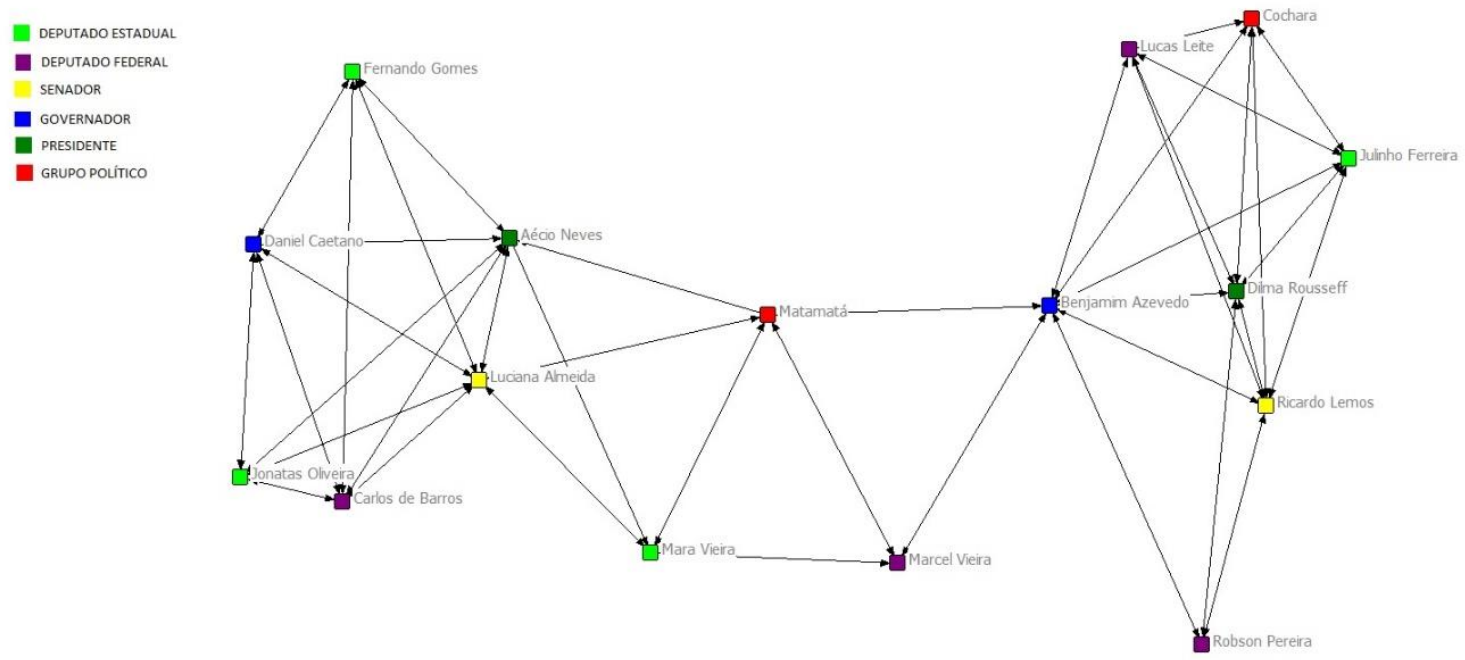

Esse mosaico de apoios complica a atuação dos cabos eleitorais. A maior parte dos cabos eleitorais que estavam presentes não apoiava pelo menos um dos candidatos do Matamatá. O cabo eleitoral João Pedro não apoiava Benjamim Azevedo, mas Daniel Caetano. O cabo eleitoral Artur Machado não apoiava Mara Vieira e nem Luciana Almeida, mas Julinho Ferreira e Ricardo Lemos. Vejamos nos gráficos que seguem:

\section{Gráfico 2 - Relação entre os grupos e os cabos eleitorais}

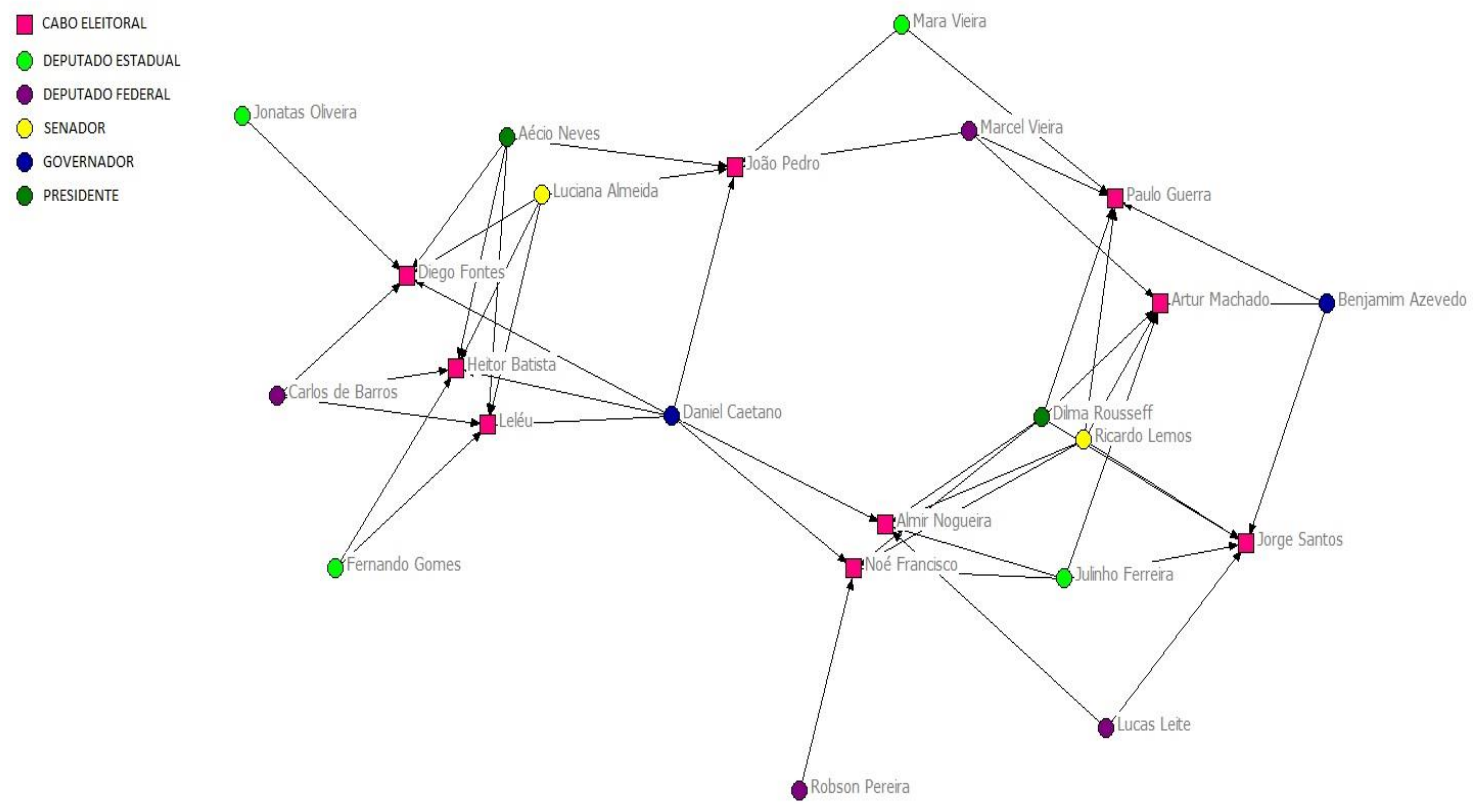


Palmeira e Heredia (2010) afirmam que a circunscrição da política como atividade legítima de todos a um período determinado inibe as atividades políticas de grupo no cotidiano. A militância permanente - marca do trabalho político dos partidos de esquerda e, no passado, também de certa direita - e até mesmo a presença muito constante do político nas comunidades é vista com desconfiança. A política é identificada com divisão (ao contrário da família, que simboliza a unidade) e, por isso, a atividade política constante é vista como uma ameaça à comunidade. Sem dúvida, aquele padrão de militância pode legitimar-se ao longo do tempo, mas trata-se de um processo difícil e de resultados incertos.

Esse caso se diferencia do caso em Arapongas, onde os políticos são chamados pela comunidade para participarem de suas ações, tanto com ajuda como também para dar credibilidade ao bairro, povoado, etc. Não quer dizer que Arapongas seja uma cidade "politizada", mas de que a política faz parte do cotidiano da cidade, não somente no "tempo da política". Os cabos eleitorais, para fazerem uma boa campanha, precisam ter um território para atuar em que já sejam conhecidos pelos seus trabalhos e que tenham quem trabalhe com eles nesses locais. Caso já tenha feito alguma festa em alguma data comemorativa, por exemplo, no dia das crianças, ou se ajudou a levar um posto de Saúde para a comunidade, isso fará com que a sua atuação tenha mais crédito no local do que outro cabo eleitoral que não tenha "feito" algo para a comunidade. E sempre com o cabo eleitoral, será levado o nome da facção a qual faz parte, uma forma indireta de fazer presente a facção, mesmo que o grupo não tenha ajudado.

A senadora Luciana Almeida falou no meio do povo; tinha pedido a palavra para falar primeiro, pois não poderia ficar durante o comício todo, uma vez que iria a outro evento em outra cidade do interior; pede voto para Mara, pelo trabalho feito na secretaria da capital. Não pede voto para nenhum outro candidato. Discurso simples, sem muitas palavras. Já com a palavra, a candidata Mara Vieira usa o nome de seu pai, falando que ele tem serviço prestado à população arapongana e à sergipana, reforçando o discurso familiar. A família foi a sua base e o fato de já ser deputada e ser formada em Enfermagem e o trabalho na área da Saúde são elementos que a faz sentir-se legitimada para continuar o trabalho na assembleia legislativa, retomando também a identidade de ser Matamatá, relembrando o trabalho de seu pai Jonas Vieira, como prefeito de Arapongas e como líder político. Esses discursos articulam a ideia de uma candidatura "involuntária" com a noção de "dever/sacrifício", ambos justificados em função do pertencimento do candidato a uma coletividade. Para ser legítimo, o candidato precisa compartilhar valores com uma determinada comunidade, seja ela de caráter local, religioso ou profissional. O papel da "comunidade" é gerar a 
candidatura do seu "líder natural". Na visão dos políticos, é o grupo que "lança" a candidatura, que "indica" o nome, que praticamente "obriga" um de seus integrantes a se tornar candidato.

Para a população em geral, pode ser que as eleições se resumam ao "tempo da política", mas quando há facções políticas que comandam o cotidiano político por meio dos seus integrantes, o "tempo da política" é todo o tempo. Considerando a política através do olhar do nativo, não há tempo sem política devido ao fato de sempre haverem atores que façam com que ela seja atemporal. Sendo assim, as campanhas e as eleições seriam o momento em que mais ela está em evidência, apesar de haver momentos em que ela consiga persistir mesmo quando não há alguém disputando algum cargo eletivo. A política é atemporal graças aos políticos que se encontram mais abaixo da hierarquia da política eletiva. Por mais que o cabo eleitoral seja considerado um ator que tenha data para poder exercer seu papel, ele não fica estagnado até o início das campanhas, até porque a todo o momento são feitos e desfeitos acordos e alianças que necessariamente alteram o percurso até a eleição ou fazem com que continue o mesmo.

A facção continua, em grande medida, a ser vista como um pré-partido tanto pelas Ciências Sociais como também pelos próprios nativos: o poder está em disputa, mas não há programas, regras rígidas de filiação, as coisas funcionam um pouco na base do estar contra ou a favor, prevalecem os interesses particulares sobre o que seria o interesse comum. Mais especificamente na Antropologia, onde as facções foram originalmente vistas como uma espécie de projeção política das linhagens em sociedades não estatais, mas com formas diferenciadas de poder, esse uso foi sendo substituído por uma visão que atribui mais autonomia às facções: grupos ou conjuntos de ação, que não incorporam apenas membros de uma linhagem, não permanentes, não são "um corpo só" que gravitam ao redor de um líder. Isso devido ao fato de as parentelas terem se desenvolvido e tido a necessidade de expandir suas alianças, criando, assim, uma rede de base familiar, como mostra Lewin (1993).

Por mais que os partidos sejam aquelas organizações nas quais os representantes são legítimos e eleitos em eleições diretas, quando se trata de política local, os mesmos perdem total visibilidade e dão lugar às facções políticas. Tanto os próprios políticos como a população não enxergam além dos grupos. Como foi falado, em Arapongas os grupos Cochara e Matamatá controlam o cotidiano da política e só se fala em partidos quando chega o momento de montar as filiações e legendas para as eleições.

A necessidade de um "patrono" para se ter acesso à esfera da política institucional é apontada como uma característica das carreiras políticas no Brasil. Por outro lado, algumas análises apontam o crescimento da influência das estruturas partidárias 
nesse contexto. A fidelidade ao partido tenderia a resultar em maiores chances de concorrer a um cargo eletivo, assim como de ter êxito na eleição (KUSCHNIR, 2000, p. 55).

Nesse caso, quando a autora fala "partido", ela se refere à organização institucional, mas durante as entrevistas, em vários, momentos a palavra "partido" era confundida com os grupos dos quais os cabos eleitorais estavam atualmente. Perguntei a eles qual o partido que eles estão ao que responderam "cochara" ou "matamatá", e mesmo quando perguntei sobre qual partido eles eram filiados, ainda teve alguns que falaram os nomes dos grupos. Para isso, precisava fazer a pergunta já dando uma resposta, mesmo que errada, como "o partido que você se encontra filiado é o PSDB? ", por mais que o ator fosse filiado a outro partido, para estimular a resposta. Não considero que eles não saibam diferenciar um partido político com um grupo/facção/agrupamento, mas devido ao fato de esses grupos estarem presentes na realidade do município desde quando os agrupamentos levavam os nomes "pebas" e "cabaús", grupos esses que estavam presentes em todo o estado.

Sobre a fidelidade a algum grupo, isso tem mudado aos poucos, e já vários atores trocaram de grupo a partir das alianças que vão sendo feitas, por exemplo, o cabo eleitoral Artur Machado, que iniciou a sua carreira política no grupo Cochara, apoiou na eleição municipal de 2008 o candidato Jonatas Oliveira para prefeito, onde esse indicou para ele o candidato a deputado estadual Julinho Ferreira, do Cochara, para as eleições estaduais de 2010. O apoio foi repetido na eleição de 2014, todavia, o CE Artur já se encontrava no grupo Matamatá, devido à derrota de Jonatas nas eleições de 2012 achou por bem "ir para o lado do prefeito".

Ninguém espera que na política local haja atores que promovam um partido e sua ideologia, tanto é que muitas vezes esses atores não seguem a pauta do partido, nem em nível estadual e nem nacional. E como antes era mais fácil de trocar de partido, muitos políticos têm um grande número de filiações partidárias em sua carreira política. Para eles, o partido serve apenas como uma "institucionalização" de suas ações enquanto um ator político. E pensando nos grupos familiares maiores, o partido seria a forma de se apresentarem nacionalmente, como forma também de controle no interior do estado, dando certa autonomia aos seus agregados, mas nunca deixando seus subordinados pois a reciprocidade deve ser mantida, devido a renovação constante que a política passa a cada ciclo eleitoral.

Devido à conjuntura partidária brasileira bastante diversa, a utilização de redes de apoio e alianças de diversos tipos é necessária para uma família ou até mesmo para várias famílias almejarem postos eletivos. Várias famílias porque na realidade sergipana, por exemplo, enquanto perdurou o coronelismo, as regiões eram regidas não somente por um coronel, mas sim por um 
conjunto de coronéis, os quais tinham o mesmo tipo de poder, e assim criava-se uma rede de base familiar, em que, de forma bastante amiúde, os vários coronéis pertenciam a uma mesma família, na qual eram inseridos parentes consanguíneos ou não (DANTAS, 1997; MONTALVÃO, 2011). Pensando nisso, podemos utilizar a ideia que Saint-Martin $(1992,2008)$ utiliza ao afirmar que tem havido um interesse, de modo crescente, pelas relações que unem ou que às vezes opõem, através de conflitos ou de lutas, os diferentes grupos dominantes, assim como pelas relações que as elites têm com outros grupos sociais e pelos modos de ação e de decisão, ou de deliberação. Logo, é visto que a necessidade de relações é de grande importância para essa manutenção e diversificação do poder; Love e Barickman (2006) demonstram as relações entre os diversos atores que faziam parte das elites regionais e como eles estavam interligados. Nesse projeto, é de suma importância corroborar as ligações entre os atores e seus grupos que fazem com que a política seja dinamizada.

Essa configuração, como já afirmaram Grill e Seidl (2013), foi sendo alterada somente pelo contexto histórico, deixando de existir a imagem do coronel e abrindo espaço para outros líderes; logo, o envolvimento com a política através da inserção em redes de relações estruturadas em torno de disputas pelo poder (facções partidárias, clubes, agremiações, sindicatos, corporações, movimentos sociais) e na burocracia pública, assim como as tomadas de posição e rupturas daí resultantes funcionam como estratégia corrente na tentativa de acúmulo de um capital simbólico ativo em diferentes espaços. Invariavelmente, a interseção que mescla princípios das lutas políticoeleitorais, da burocracia do Estado e de carreiras profissionais assenta-se em relações de reciprocidade, fundamentalmente, o "clientelismo" e a "patronagem".

\section{CONSIDERAÇÕES FINAIS}

Com o objetivo de debater sobre a relação entre os agrupamentos e famílias políticas e redes sociais que constituem o quadro político-partidário do estado de Sergipe partindo tanto da política local e de como ela se insere no contexto estadual, foi tentado mostrar aqui como os grupos políticos, liderados por famílias e seus agregados continuam constituindo o quadro político estadual através de uma mobilidade disfarçada, pelo menos no que concerne à política e em um dos aspectos da mesma, já que essa acaba enquadrando vários elementos. Essa mobilidade apresentada foi colocada em mãos do cabo eleitoral, que acaba conversando com políticos variados e grupos muitas das vezes divergentes. Pelo menos a nível local, a participação de integrantes de outros agrupamentos acaba sendo aceita com a ideia de que "quanto mais, melhor", apesar de que esses 
cabos eleitorais buscam também a sua participação e visibilidade, por serem considerados lideranças locais.

Quanto aos políticos, buscam não dar tanta atenção a essas divergências, devido ao fato de que não se pode levar em consideração somente a sua terra de origem, mas necessita pensar no contexto estadual, levar o seu nome para outros municípios, criando-se uma identidade, mesmo sem se desprender dos seus antepassados. A capacidade de obtenção de apoio por parte desses agrupamentos demonstra que é importante a participação de agregados, para manutenção e ampliação de suas redes, pois como o "tempo da política" se renova a cada ciclo, ter um agrupamento espalhado em vários espaços é uma estratégia que consegue ser atemporal, pois o recurso humano se adapta a qualquer tempo e necessidade.

\section{REFERÊNCIAS}

BACOT, Paul. En haut et du mauvais côté. Les professionnels de la politique au miroir des citoyens. In. Offerlé, M. La profession politique. XIXe-XXe siècles, Paris, Belin, 1999.

BECKER, Howard. Outsiders. Rio de Janeiro: Zahar, 2008.

BEZERRA, Marcos. Em nome das bases. Política, favor e dependência pessoal. Rio de Janeiro: Relume Dumará, 1999.

BLONDEL, Jean. As condições da vida política no Estado da Paraíba. Rio de Janeiro:

FGV, 1957.

BRIQUET, Jean-Louis. "L'imperatif du changement. Critique de la classe politique et renouvellement des parlementaires dans la crise italienne (1992-1994)". In. OFFERLÉ, M. La profession politique XIXe-XXe siècles, Paris, Belin, p. 93-134, 1999.

CAMARGO, Carla. Partidos e grupos políticos num município do sertão de Pernambuco. Dissertação (Mestrado), Universidade Federal de São Carlos: São Carlos, 2012.

CANDIDO, Antonio. The Brazilian Family. IN: Smith, T. L. e Marchant, A. (Eds), Brazil, portrait of a continent . N. Y.: The Dryden Press, 1951

CANEDO, Letícia. Herança na política ou como adquirir disposições e competências necessárias às funções de representação política (1945-1964). Pro-Posições - vol. 13, n. 3 (39) set./dez. 2002.

. Heranças e aprendizagens na transmissão da ordem política brasileira. Cadernos CERU, série 2, no 15, 2004.

. Um capital político multiplicado no trabalho genealógico. Revista Pós

Ciências. Sociais, v.8, n.15, jan./jun. 2011.

CARVAlHO, José M. Mandonismo, Coronelismo, Clientelismo: Uma Discussão Conceitual.

Dados vol. 40 no. 2. Rio de Janeiro, 1997.

CORADINI, Odaci. Em Nome de Quem? Recursos sociais no recrutamento de Elites

Políticas. Rio de Janeiro: Relume Dumará, 2001.

DANTAS, Ibarê. A Tutela Militar em Sergipe (1964-1984). Rio de Janeiro: Tempo

Brasileiro, 1997.

DUBAR, Claude. A socialização: construção das identidades sociais e profisssionais. Portugal: Porto editora, 1997 
GRILL, Igor G. Processos, Condicionantes e bases sociais da especialização da política no Rio Grande do Sul e no Maranhão. $31^{\circ}$ Encontro Anual da ANPOCS; Seminário Temático 16: Elites e Instituições Políticas. 22 a 26 de Outubro de 2007, Caxambu, MG.

2008. "Heranças Políticas" no Rio Grande do Sul. São Luís: EDUFMA,

. As Bases das Heranças Políticas no Rio Grande do Sul: parentesco, partidos e redes. Sociedade em Debate, Pelotas, 10(2): 160 159-197, ago./2004.

. "Famílias", ascensão social e alinhamentos partidários no Rio Grande do Sul. Revista de Ciências Sociais, Fortaleza, v. 43, n. 2, jul/dez, 2012, p. 137 - 157.

GRILL, I. SEIDL, Ernesto. A Política como objeto de estudo das ciências sociais.

IN: GRILL \& SEIDL. As Ciências Sociais e os Espaços da Política no Brasil. Rio de Janeiro: FGV, 2013.

HUGHES, Everett. Men and their Works. Collier-Macmillan Canada, Ltd.: Toronto, Ontario, 1964.

KUSCHNIR, Karina. O Cotidiano da Política. Rio de Janeiro: Jorge Zahar, 2000.

LANDÉ, C.H. "Introduction: the dyadic basis of clientelism". In: SCHMIDT, S.W. etalli. (Eds.).

Friends, Followers and Factions. A Reader in political clientelism. Berkeley, University of California Press, 1977.

LEHINGUE, P.Vocation, art, métier ou profession? Codification et étiquetage des activités politiques. In. OFFERLÉ, M. La profession politique XIXe-XXe siècles, Paris, Belin, p. 93-134, 1999.

LEWIN, Linda. Política e Parentela na Paraíba: Um Estudo de Caso de Oligarquia de Base Familiar. Trad. André Villalobos. Rio de Janeiro: Record, 1993.

LOVE, Joseph. BARICKMAN, Bert. Elites Regionais. IN: HEINZ, Flávio. Por outra história das elites. Rio de Janeiro: FGV, 2006.

MONTALVÃO, Arivaldo. Recrutamento de elites parlamentares em Segipe: deputados da ARENA (1965-1979). Dissertação (Mestrado em Sociologia). Programa de Pós Graduação em Sociologia. Universidade Federal de Sergipe: São Cristóvão, 2011.

OFFERLÉ, Michel. Profession et Profession Politique. In. OFFERLÉ, M. La profession politique XIXe-XXe siècles, Paris, Belin, p. 93-134, 1999.

PALMEIRA, Moacir. Política, Facções e Voto. In. PALMEIRA \& GOLDMAN (coord).

Antropologia, voto e representação política. Rio de Janeiro: Contra-capa Livraria, 1996.

PALMEIRA, Moacir. BARREIRA, César. Política no Brasil: visões de antropólogos. Rio de Janeiro: Relume Dumará, 2004.

PAlMEIRA, Moacir. HEREDIA, Beatriz. Política Ambígua. Rio de Janeiro: Relume Dumará, 2010.

PETRARCA, Fernanda. De Coronéis a Bacharéis: reestruturação das elites e medicina em Sergipe (1840-1900). Revista Brasileira De História (Online), p. 89-112, 2017.

QUEIROZ, Ma . I. P. de. O mandonismo local na vida política brasileira e outros ensaios. São Paulo: Editora Alfa-Omega, 1976.

PHELIPPEAU, Eric. Sociogênese da Profissão Política. IN: GARRIGOU, A \& LACROIX, B. Norbert Elias: a política e a história. São Paulo: Perspectiva, 2010.

SAINT MARTIN, Monique de. "Da reprodução às recomposições das elites: As elites administrativas, econômicas e políticas na França". In. Revista Tomo, n. 13 jul./dez.,

2008,São Cristóvão. (p. 43 - 73).

A nobreza na França. A tradição como crença. Revista Brasileira de Ciências Sociais, 20, 1992, (p. 148-162). 
SANTOS, Pâmella S. S. O ofício de cabo eleitoral: entre campanhas, comícios e o dia a dia da política. Dissertação (Mestrado em Sociologia), Programa de Pós-Graduação em Sociologia Universidade Federal de Sergipe: São Cristóvão, 2016.

SAWICKI,Frédérick. Classer les hommes politiques. Les usages des indicateurs de position sociale pour la compréhension de la professionnalisation politique. In. OFFERLÉ, M. La profession politique XIXe-XXe siècles, Paris, Belin, p. 93-134, 1999. 